\title{
Factors influencing post abortion outcomes among high-risk patients in Zimbabwe
}

\author{
C Mudokwenuy-Rawdon, D Litt et Phil student, \\ Department of Health Studies, UNISA and Senior Lecturer, Faculty of Nursing, University of Zimbabwe.
}

VJ Ehlers, D Litt et Phil.

Department of Health Studies, UNISA

MC Bezuidenhout

Department of Health Studies, UNISA

\section{Keywords:}

abortion, anaemia. case fatality rate, post abortion sepsis quality care, post abortion risk factors, post abortion complications
Correspondence address:

Dr VJ Ehlers

POBox 65075

ERASMUSRAND

0165

Tel: 012-347-8287 (home)

Fax:012-347-8287

E-mail:bvgrain@mweb.co.za (home)

\section{Abstract: Curationis 28(4): 74-85}

Post abortion complications remain one of the major causes of mortality among women of child bearing age in Zimbabwe. Based on this problem, factors associated with mortalities due to abortion were investigated with the aim of improving post abortion outcomes for Zimbabwe's women, and possibly also for women of other African countries. Cases and controls were selected from 4895 post abortion records to conduct a retrospective case-control study. Significant risk factors identified for reducing mortalities due to post abortion complications included the administration of oxytocic drugs and evacuation of the uterus whilst anaemia and sepsis apparently reduced these women's chances of survival. Women who died (cases) from post abortion complications apparently received better reported quantitative care than controls. Recommendations based on this research report include improved education of health care workers and enhanced in-service training, regular audits of patients' records and changed policies for managing these conditions more effectively in Zimbabwe.

\section{Opsomming}

Komplikasies na aborsie is steeds een van die hoof oorsake van mortaliteit in vrugbare Zimbabwiese vroue. Gebaseer op hierdie probleem, is die faktore wat verband hou met mortaliteit weens aborsies ondersoek met die doel om na-aborsie uitkomste vir Zimbabwiese vroue, en moontlik ook vir vroue in ander Afrika lande, te verbeter. Gevalle en kontrole respondente is geselekteer uit 4895 rekords van vroue wat aborsies ondergaan het. ten einde ' $n$ retrospektiewe gevalle-kontrole studie te onderneem. Betekenisvolle risiko faktore, wat geidentifiseer is met die doel om mortalitiet as gevolg van aborsie komplikasies te verminder, was die toediening van oksitosien geneesmiddels en lediging van die uterus, terwyl anemie en sepsis skynbaar die vroue se kanse op oorlewing verminder het. Vroue (gevalle) wat weens aborsie gesterf het, het volgens hul rekords, waarskynlik beter kwantitatiewe sorg ontvang as die kontrole respondente. Aanbevelings gebaseer op die navorsingsverslag sluit onder andere in verbeterde opleiding van gesondheidsorgwerkers, versterking van indiensopleiding, gereelde ouditering van pasiënte se rekords en gewysigde beleid vir die doeltreffende hantering van diè toestande in Zimbabwe.

Sleutelwoorde: aborsie, anemie, sterftesyfergevalle, na-aborsie sepsis gehalte sorg, na-aborsie risiko faktore, na-aborsie komplikasies 


\section{Introduction}

Abortion implies the spontaneous or induced termination of a pregnancy before the foetus is viable (Oxford Handy Dictionary 1991:2). Most abortions occur during the first trimester of pregnancy. If some of the products of conception are retained in the uterus, it is referred to as being an incomplete abortion (Bennett \& Brown 1999:272). Pregnant women who undergo illegal (often back street abortions) are at risk of suffering from complications such as perforation of the uterus, sepsis, haemorrhage and death. In Zimbabwe women cannot access legalised termination of pregnancy services, and might thus be compelled to seek back street abortions. As abortions remain illegal in Zimbabwe, women would not admit to seeking back street abortionists' services for fear of prosecution. Consequently this study could not distinguish between different types and/or causes of abortions. It focused on factors influencing post abortion outcomes among high risk patients in Zimbabwe, with the ultimate aim of contributing towards reducing the mortality and morbidity associated with post abortion outcomes in Zimbabwe.

\section{Rationale for conducting the study}

Every year 600000 women die from causes associated with pregnancy and childbirth (WHO 1999:1). Almost 90,0\% of these maternal deaths occur in Sub-Saharan Africa (SSA) and Asia (Starrs 1997:1). The World Health Organization (WHO) estimated that 20 million abortions each year are unsafe and that $10-50 \%$ of these women require subsequent medical care for post abortion complications (WHO 1994:1). "Approximately 13\% of pregnancy-related mortality worldwide is due to unsafe abortions and the majority of these deaths (and morbidity) occur in developing countries where abortion is limited by law; $20-25 \%$ of all maternal deaths in Asia, $30-35 \%$ of all maternal deaths in Africa and Latin America and 25-30\% of all maternal deaths in Russia are believed to be the result of induced abortion" (May, Gulmezoglu \& Ba-Thike 2000:1). A Zimbabwean study by Ashworth (1990:211) indicated that abortion and severe pre-eclampsia/ eclampsia accounted for the majority of pregnancy-related deaths in Zimbabwe, similar to reported global causes for pregnancy-related deaths (WHO 1999:13). With respect to abortion, global estimates showed that from 100000 to 200000 women die every year due to abortion related complications (AbouZahr \& Royston 1991:9). According to the WHO (1998a: 2), about 80000 of these deaths were due to unsafe abortions, most of which occurred in developing countries. For example, annually in Eastern, Western and Central Africa between 28 and 36 unsafe abortions were estimated to occur for every 1000 women aged 15 to 49 years (WHO 1998a:2). In Zimbabwe at Mpilo Central Referral Hospital (MCRH), situated in the city of Bulawayo, out of 116 recorded obstetric deaths, 39.6 percent were abortion-related deaths (MCRH Obstetric Records 1997). The fact that some high-risk women died and others survived was the reason for conducting this study, in order to identify factors discriminating between nonsurviving (cases) and surviving (controls) women hospitalised at MCRH with post abortion complications. The factors considered in this study focused mainly on two aspects, namely: pathophysiological conditions (haemoglobin level, sepsis), and the treatment and standard of care recorded (oxytocic drugs, antibiotics, blood transfusion, evacuation of the uterus, emergency care administered, regular observations of blood pressure, pulse and temperature). These factors were compared for cases (women who died from post abortion complications) and for controls (women who survived these complications) in Mpilo Central Referral Hospital (MCRH) in Bulawayo, Zimbabwe. This study was deemed essential, as termination of pregnancies remain illegal in Zimbabwe, many women might continue to seek illegal (backstreet) abortions in order to terminate unwanted pregnancies. As long as this situation exists, women will present with high risk post abortion complications at hospitals in Zimbabwe. Improving the quality of care rendered to these women, might reduce the number of deaths from high risk post abortion complications.

\section{Research questions and hypotheses}

Based on an in-depth literature study, knowledge of maternal mortality statistics in Zimbabwe, extensive experience in midwifery and gynaecological hospital departments in Zimbabwe, experience of teaching midwifery students in Zimbabwe, and supervising master's students doing research projects throughout Zimbabwe, research questions were formulated. These questions were discussed with obstetricians at the University of Zimbabwe and with medical and midwifery colleagues working in different locations throughout Zimbabwe. The aim of these discussions was to determine whether the research would be feasible and whether the research results could be expected to make any contribution towards reducing the post-abortion mortality and morbidity statistics in Zimbabwe. The revised research proposals were discussed with nurse researchers and with a statistician.

The specific research questions which guided this research were:

- Is there a difference in selected factors associated with matemal mortality due to post abortion complications between non-surviving (cases) and surviving (controls) women hospitalised at MCRH?

- Is there a difference in selected aspects of the standard of care received by non-surviving (cases) and surviving (controls) women hospitalised for post abortion complications at MCRH?

The following hypotheses, formulated prior to conducting the research, were posed for this study:

- There is a difference in selected patho-physiological factors (low haemoglobin levels and raised temperatures) associated with matemal mortality due to post abortion complications between non-surviving (cases) and surviving (controls) women hospitalised at MCRH.

- There is a difference in selected aspects of standard of care received by non-surviving (cases) and surviving women (controls) hospitalised for post abortion complications at MCRH.

- The association of selected aspects of health care factors (emergency care, oxytocic drug treatment, blood transfusion, evacuation of the uterus) with mortality due to post abortion complications in cases and controls hospitalised at the 
MCRH will hold after adjusting for specific (potential) confounding variables (residence, age, marital status, occupation, gravidity).

\section{Conceptual framework}

Donabedian's (1989:3-11) model was used to guide the study. The aim was to gain information regarding the structure, process and outcome in order to evaluate the influence of specific factors on the outcomes of high risk women admitted to MCRH with post abortion complications. Using the Donabedian (1989:3-11) model the women's demographic characteristics (age, marital status, education level and employment status) and physiological factors (haemoglobin, temperature and blood pressure levels) were classified under structure. This is because women with high-risk pregnancy conditions also present with their personal characteristics including pathophysiological factors, which might influence pregnancy outcomes. Health care interventions (including medicalsurgical treatments and nursing care) recorded on patients' charts, formed a basis for evaluating the quality of care rendered to women during their hospitalisation in MCRH (Donabedian 1988: 1746). Deaths (cases) and survivors (controls) from post abortion complications were the outcome variables for this study. This approach emphasised the interdependence between Donabedian's principles of structure, process and outcome, which could either be used singly or combined in a study focusing on factors influencing the post abortion outcomes among high risk patients in Zimbabwe. Used in this way, Donabedian's model was used to study not only the effects of nursing care but also of medical-surgical interventions (process variables) as factors influencing the post abortion outcomes among high risk women (outcome variables) against the background knowledge of these women's patho-physiological conditions (structure variables).

\section{Literature review}

The world-wide emphasis on reducing maternal mortality rates (MMRs) has focused on quality of health care as an essential means of reducing MMRs. Banta (1992:25) states that "...the term quality is often used in different ways and may denote characteristics such as effectiveness, efficacy, equity, acceptability, accessibility, adequacy, and scientific/technical quality." According to the Oxford Advanced Learners' Dictionary (1989: 1023), quality is "... the degree of goodness or worth." The Nurses' Association of the American College of Obstetricians and Gynaeologists (NAAOG) refers to quality as a "...state of agreed-upon excellence" (NAAOG 1990:2). In health care, quality is about achieving pre-set standards, which in turn satisfy both consumers and providers of health care services. Quality is relevant to health research in order to continually establish, maintain or improve the standards of services rendered.

One way of assessing the quality of care rendered is through the auditing of clinical records. This survey, which utilised a retrospective case control approach, could be regarded as one way of auditing clinical records, and thus of assessing the clinical care as recorded on the patients' records. Bennett and Brown (1999:117) proposed a clinical audit, involving the evaluation of patients' records concurrently during their treatments or retrospectively after discharge. The emphasis is on systematic evaluation of the care rendered to patients based on what is written in their records. The underlying assumption is that care recorded reflects care rendered, and care not recorded reflects care not rendered. The assessment is based on the assumption that care given is accurately documented. Records, as a source of data, must respond to a pre-developed set of questions, procedures, and checklists focusing on the type of patient care to be assessed. The clinical record audit possesses more attributes that suited this study than any other research method. This study relied on records for information about aspects of care, associated with post abortion mortality or survival, by means of using a retrospective case-control design applying Donabedian's (1989:99) principles of structure, process and outcome.

As Abramson (1990:480) stated “... the quality of health care may be judged from information about effects (outcome evaluation), about the performance of activities (process evaluation), or about facilities and setting (structure evaluation)." Termination of pregnancy services remain illegal in Zimbabwe.
Therefore women who wish to terminate unwanted pregnancies need to resort to illegal, usually back street, abortion services where there are no controls over hygienic measures nor about the credentials of the persons performing these abortions. The only way of studying factors influencing the outcomes of women suffering from post abortion complications seemed to be to study the records of the care provided and to compare the records of those who died (cases) with those who survived (controls) in an effort to suggest treatment protocols which could enhance women's chances of surviving post abortion complications in Zimbabwe, and possibly also in other developing countries.

\section{Research methodology}

In this section the research design, research population and sample, sampling techniques, research setting, research instruments, ethical issues, research procedure and data analysis will be addressed.

\section{Research design}

A quantitative retrospective unmatched case-control design was used to compare two groups (cases and controls) of post abortion women at the MCRH.

\section{Research population, sample and sampling technique}

The research population comprised 4895 admissions for post abortion complications. During this period (1 January 1995 till 31 December 1997) there were 46 deaths recorded due to post abortion complications. Permission was granted by the MCRH's authorities that files for this period of time could be used for the research. Using more recent files might, according to their explanations, contribute to disruptions in the day-today functioning of the hospital should any person's (control's) file be unobtainable because the researcher was using it at that specific time. As hospital treatment protocols for post abortion complications remained relatively unchanged since 1995, the researcher had to accept this limitation imposed on the availability of the patients' records. Having established that hospital treatment protocols for post abortion complications remained the same since 1995, this was not expected to have any major impacts on the validity of the data to be retrieved from the patients' files. 
The sample was drawn from hospital obstetric records of women who were admitted with post abortion complications from 1 January 1995 till 31 December 1997. For every case, two controls were selected. Major problems were encountered in tracing the records of patients. As patients' records were not computerised the physical files had to be found. This posed major problems in tracing specific patients' files as some files were reportedly being reviewed by hospital management, while others were simply not available, being either lost or misfiled. After many weeks of searching in MCRH's archives only 20 post abortion cases' and 40 controls' files could be traced. The initial plan of matching each case with two controls for age, parity, level of education and urbannural residence had to be abandoned.

\section{Research setting}

The study site was MCRH in Bulawayo, which is the second largest city in Zimbabwe, lying in the south western part of the country. The hospital is one of the two large central referral hospitals for high-risk patients in Zimbabwe (MOH, Zimbabwe 1981:45). The MCRH has a total bed capacity of 1038 of which 38 are for gynaecological patients. Although the gynaecological ward has 38 beds, it usually exceeds its capacity resulting in a high bed occupancy rate. In 1996, the bed occupancy rate was 92.5\% while the length of stay was 6.3 days. Analysis of the data shows that a major cause of obstetric deaths $(39.6 \%)$ related to post abortion complications (MCRH Annual Report, Zimbabwe 1996:16).

\section{Research instruments}

Two research instruments were used, namely a hospital census form and an obstetric record form. The census data obtained information about the hospital's facilities, annual admissions, deliveries, live births and obstetric deaths from the MCRH registers. The obstetric record audit form was used to collect data about factors that could influence post abortion outcomes for cases and controls respectively.

An experienced masters prepared midwifery lecturer, two statisticians, and two nurse researchers assessed the content validity. The format was then submitted to these experts for final review and there was more than $80.0 \%$ agreement on relevancy of the items
(Talbot 1995:282). The instrument was pre-tested using 5 obstetric records of cases (women who died) at MCRH, and two controls (women who survived) for each case. These pre-test records of both cases and controls were excluded from the actual survey.

The obstetric records audit forms captured data from the sample focusing on socio-demographic factors (residence, age, marital status, educational level, occupation), pathophysiological factors (haemoglobin level, blood pressue, temperature) and obstetric/gynaecological factors (gravidity, gestational age, type of abortion). Health service factors comprised interventions regarding abortion criteria for measurement of the standard of care based on a review of relevant literature. Specific criteria utilised focused on abortion care as advanced by Winkler, Oliveras and McIntosh (1995:1-4). The variables of interest included contraceptives used, antenatal care booking status (booked or unbooked), post abortion emergency care (summoning medical assistance, quarter to half hourly observations of blood pressure, temperature, respiration and pulse), oxytocic drug administration, blood transfusion, antibiotics, analgesic drugs, follow-up care (hourly to four hourly observations of blood pressure, temperature, respiration and pulse), evacuation of the uterus, evidence of medical reviews and documentation (or omission of documentation) of care provided.

\section{Ethical issues}

Approval for the research, was requested from and granted by the Medical Research Council of Zimbabwe and the Mpilo Central Referral Hospital authorities, subject to the limitation that only records from 1 January 1995 till 31 December 1997 could be used to gather data for the study. The study inflicted no harm on the subjects nor on their relatives as no names were disclosed to ensure confidentiality. A coding system was used to ensure anonymity of patients and the data collected were used strictly for the purpose for which it was collected. No specific person was mentioned in the discussion of the findings. Only the researcher and the research assistant could trace the recorded data on a specific checklist to any specific patient's file. The list correlating a specific checklist's number with a specific patient's file number was kept locked up by the researcher until after publication of the research results when it was destroyed.

\section{Research procedure}

The post abortion cases' and the controls' hospital numbers were identified from the admission and death registers. This information enabled the investigator to retrieve the cases' and controls' obstetric records from the hospital records office. These records were subjected to thorough scrutiny in a separate office not accessible to anyone except the investigator and research assistant. Each case was given a code number, which it shared with its selected two controls to avoid using the same controls twice for another case (for example case $=1$, controls $=\mathrm{I} \mathrm{a}$ and $\mathrm{Ib}$ ). These codes served to ensure anonymity throughout the research process and to avoid the repetitive use of the same records.

\section{Data analysis}

The data was organised for analysis under post abortion cases and controls. Odds ratio (OR) and $95 \%$ confidence intervals $(95 \% \mathrm{CI})$ were estimated according to the Mantel-Haenszel ChiSquare Test or Fischer's Exact Test (Kahn \& Sempos 1989:155). A separate analysis was performed using stepwise logistic regression analysis to take into account the effect of possible confounding variables such as residential area (urban or rural), age, marital status, and occupation status. The OR was used to measure the impact of a possible risk factor. Possible categories for OR were greater than one or less than one (Kahn \& Sempos 1989:56). When the value of OR was greater than one, there was a significant increased risk between mortality due to post abortion complications and the specific factor. On the other hand, when the OR was less than one this risk was reduced. This implied that there was no association between death due to post abortion complications and the specific factor (Khan \& Sempos 1989:56). (The independent variables were expressed as $\mathrm{OR}, 95 \%$ Confidence interval $(\mathrm{CI})$ and $\mathrm{p}$ values to demonstrate the magnitude of the risk of maternal mortality risk). Twotailed tests for normal distribution for differences between proportions of cases and controls were used to allow comparative analysis to be reviewed, analysed and reported (Polit \& Hungler 
1995:408). Stepwise logistic regression tests were used to test for further significance of variables and to determine whether the correlation of factors associated with deaths still held after controlling for confounding variables (urban and rural residence, age, marital status, education, occupation status, gravidity) as suggested by Munro (1997:292)

\section{Research results}

The total sample of post abortion cases (20) and controls (40) comprised 60 records. The findings pertaining to some variables, namely emergency care (quarter to half hourly observation of blood pressure, temperature, respiration and pulse) and blood transfusion, appeared to be contradictory to expectations. These variables remained significant after the stepwise logistic regression analysis had been applied.

\section{Socio-demographic factors Urban-rural residence}

In both post abortion cases (20) and controls (40), the majority, $(90,0 \%$ and $82,5 \%$ respectively) were from the urban setting. There were no statistically significant differences in maternal mortality risk due to abortion between women who were from the urban and those from the rural settings ( $\mathrm{p}$-value = $0.571, \mathrm{OR}=1.64,95 \% \mathrm{CI}=0.25-13.37$ ).

\section{Age}

The mean age of the cases was 30.1 years, mode 23 years, ranging from 15 to 49 years $(S D=8.454)$. Out of the 20 cases, $10(50,0 \%)$ were aged between 30-39 years. The mean age for the controls was 25.6 years while the mode was 21 years and range was 15 to 41 years $(S D=6.400$ ). Six $(30,0 \%)$ of the 20 cases were in the age group 20 to 29 years compared to 28 (70,0\%) of the 40 controls. The women's age of $>30$ years was statistically significant $(\mathrm{p}$-value $=0.009, \mathrm{OR}=4.50$, $95 \% \mathrm{CI}=1.24-16.56$ ) as a risk for mortality. There were considerably more cases $(60,0 \%)$ than controls $(25,0 \%)$ whose ages were above the mean. In this study, the proportions of abortions were greatest among the 30 to 39 years age group for the cases and 20 to 29 years for the controls. It would seem that age was a greater risk factor for maternal mortality among older women than among younger women.

\section{Level of education}

Educational background was not recorded in $95,0 \%$ of cases' and $87,5 \%$ of controls' records. Education level was not weighted to determine the risk for death because of insufficient recorded data. The researcher's inability to obtain information not recorded on the patients' records made this anticipated comparison of cases' and controls' attained levels of education impossible.

\section{Employment}

The majority of both cases $(95,0 \%)$ and controls $(100,0 \%)$ were not formally employed, rendering it statistically inappropriate for providing meaningful comparisons between cases and controls.

\section{Marital status}

Large numbers of both cases $(60,0 \%)$ and controls $(55,0 \%)$ were single, divorced, widowed or separated, implying that more than half of these women did not have husbands at the time of admission for post abortion complications. As reasons for abortions were not recorded, no inferences could be drawn about the possible relationship between marital status and such reasons.

\section{Physiological factors}

The analysis specific to haemoglobin ( $\mathrm{Hb}$, blood pressure (BP) and temperature was expressed in grams per deciliter $(\mathrm{g} / \mathrm{dl})$, millimeters of mercury $(\mathrm{mm}$ $\mathrm{Hg}$ ) and in degrees Celsius $\left({ }^{\circ} \mathrm{C}\right)$ respectively. In this study, the normal $\mathrm{Hb}$ level was defined as $>11 \mathrm{~g} / \mathrm{dl}$ and temperature as ranging between 36 and $37.5^{\circ} \mathrm{C}$. A systolic blood pressure (SBP) of 120 and a diastolic blood pressure (DBP) of $60 \mathrm{~mm} \mathrm{Hg}$ were considered to be within the normal range. These levels were accepted as normal based on data portrayed in the literature and on the levels accepted as normal in the daily obstetric/gynaecological practice at the Mpilo Central Referral Hospital.

\section{Haemoglobin level}

Eight $(40,0 \%)$ cases' compared to 11 (32,5\%) controls' $\mathrm{Hb}$ levels were recorded as $7 \mathrm{~g} / \mathrm{dl}$ or less. Four $(20,0 \%)$ cases and $5(12,5 \%)$ controls' had no Hb levels recorded. The mean $\mathrm{Hb}$ for the cases was $8.8 \mathrm{~g} / \mathrm{dl}$ and the mode was $7 \mathrm{~g} / \mathrm{dl}$. For the 40 controls, the mean was $9.7 \mathrm{~g} / \mathrm{dl}$ while the mode was $12.0 \mathrm{~g} / \mathrm{dl}$. Eleven $(55,0 \%)$ of the 20 cases had $\mathrm{Hb}$ of $\leq 11 \mathrm{~g} / \mathrm{dl}$ compared to $19(47,5 \%)$ of the 40 controls. The $\mathrm{Hb}$ level ranged from 4 to $15 \mathrm{~g} / \mathrm{dl}$ for the cases and from 3 to $15 \mathrm{~g} / \mathrm{dl}$ for the controls.
The $\mathrm{Hb}$ readings alone did not portray significant differences between those of the cases and the controls, except that the mode for the cases was $7 \mathrm{~g} / \mathrm{dl}$ while it was $12 \mathrm{~g} / \mathrm{dl}$ for the controls, and the mean for the cases was $8,8 \mathrm{~g} / \mathrm{dl}$ while it was 9,7 $\mathrm{g} / \mathrm{dl}$ for the controls. Thus it seemed possible that more cases (than controls) might have encountered critical problems because of low $\mathrm{Hb}$ levels, possibly aggravated by blood loss.

Haemoglobin was dichotomised at levels of $f £ 11.0 \mathrm{~g} / \mathrm{dl}$ as reflecting anaemia and $>>11.0 \mathrm{~g} / \mathrm{dl}$ normal $\mathrm{Hb}$ levels. There was no significant association of anaemia with mortality resulting from post abortion complications between the two groups (p-value $=0.335, \mathrm{OR}=1.85,95 \%$ $\mathrm{CI}=0.46-8.21$ ). The number of cases, however, with anaemia was higher than that of controls $(68,8 \%$ versus $54,3 \%)$, an issue to be considered when evaluating the outcomes of administering blood transfusions to women with post abortion complications.

\section{Blood pressure}

When the BP was analysed, the mean SBP was $130 \mathrm{~mm} \mathrm{Hg}$ for both cases and controls. The median was $133 \mathrm{~mm} \mathrm{Hg}$ for the cases while it was $124 \mathrm{~mm} \mathrm{Hg}$ for the controls. Three $(15,0 \%)$ of the 20 cases had SBP $>140 \mathrm{~mm} \mathrm{Hg}$ and one's (5.0 percent) blood pressure had not been recorded. Out of the 40 controls, five $(12,5 \%)$ had SBP of $\geq 140 \mathrm{~mm} \mathrm{Hg}$. Two cases $(10,0 \%)$ had DBP of $<60 \mathrm{~mm} \mathrm{Hg}$ compared to none of the controls. The majority $(80,0 \%)$ of the cases had a DBP ranging from 60 to $74 \mathrm{~mm} \mathrm{Hg}$ while the range for the largest proportion $(45,0 \%)$ of controls was between 75 to $84 \mathrm{~mm} \mathrm{Hg}$. The DBPs recorded for both cases and controls fell within the acceptable normal ranges, except for the two cases with DBPs below $60 \mathrm{~mm} \mathrm{Hg}$.

In terms of the SBP being above or below $140 \mathrm{~mm} \mathrm{Hg}$, there was no significant difference in survival status suggesting that a woman's SBP might not have been associated with the risk of maternal death ( $p$-value $=0.524, \mathrm{OR}=0.59,95 \% \mathrm{CI}=0.09$ 4.56). The DBP of a woman appeared to have no significant influence on the post abortion outcomes (p-value $=0.124, \mathrm{OR}$ $=2.51,95 \% \mathrm{CI}=0.66-9.67)$.

\section{Temperature}

When temperature levels were analysed, $12(60,0 \%)$ of the 20 cases had temperature levels of $39^{\circ} \mathrm{C}$ and higher compared to 19 
$(47,5 \%)$ of the 40 controls. The range distributions for cases were between 36 to $41^{\circ} \mathrm{C}$ and 36 to $40^{\circ} \mathrm{C}$ for the controls. The mean temperature of the cases was $41.5^{\circ} \mathrm{C}$ while $38^{\circ} \mathrm{C}$ was noted as the mean for the controls.

Temperature levels that were used in the analysis were at levels $\leq 36.0^{\circ} \mathrm{C}$ and $>37.5^{\circ} \mathrm{C}$. Temperature levels between 36 ${ }^{\circ} \mathrm{C}$ to $\leq 37.5^{\circ} \mathrm{C}$ were considered to fall within normal ranges while $>37.5^{\circ} \mathrm{C}$ described women who were pyrexial. Pyrexia as a risk factor for maternal mortality was statistically significant (pvalue $=0.043 ; \mathrm{OR}=3.25 ; 95 \% \mathrm{CI}=0.90$ 12.51). Based on the OR confidence interval of 0.90-12.51 (including 1), women with a temperature $>37.5$ seemed more likely to die from post abortion complications. As $68,4 \%$ of cases, compared to $40,0 \%$ of the controls, were pyrexial the clinical importance of elevated temperatures among post abortion women cannot be overemphasised.

\section{Obstetric/gynaecological factors}

The gravidity, gestational period and whether the abortion was septic, non septic or unclassified were analysed under this section as variables for comparing the risk associated with death versus the chances of survival among women with post abortion complications admitted to the Mpilo Central Referral Hospital.

\section{Gravidity}

Eight $(40,0 \%)$ of the cases were gravid four and above compared to eight $(20,0 \%)$ of the controls. This finding could indicate that maternal risk, due to post abortion complications, increases with gravidity $(\mathrm{p}$-value $=0.236, \mathrm{OR}=2.00,95 \%$ $\mathrm{Cl}=0.54-7.24$ ).

\section{Gestational period}

The majority of abortions in both cases $(70,0 \%)$ and controls $(75,0 \%)$ occurred in the first trimester. The risk of abortion appeared to increase with the increased period of gestation because, slightly more cases $(30,0 \%)$ aborted in the second trimester compared to $25,0 \%$ of the controls. However, the statistical test results showed that there was no significant risk of maternal death due to abortion associated with gestational period $(p$-value $=0.682, O R=0.78,95 \%$ $\mathrm{CI}=0.21-3.17$ ).

\section{Septic, non-septic or unclassified abortions}

Nine $(45,0 \%)$ out of 20 cases developed sepsis compared to $20(50,0 \%)$ of the controls. This proved to be an unexpected finding implying that fewer cases than controls had sepsis.

In terms of the type of abortion, women were classified under septic or non-septic abortion. In these two groups of women, the results showed that there was no statistically significant difference in maternal mortality or survival status ( $\mathrm{p}$ value $=0.357, \mathrm{OR}=0.56,95 \% \mathrm{CI}=0.14$ 2.27). There were more respondents within the control group $(66,7 \%)$ who reportedly had septic abortions than cases $(52.9 \%)$ according to the patients' recorded information. This result appeared to contradict the indication that more cases than controls had pyrexia. This apparent discrepancy could not be accounted for from the available records. However, the validity of the classification of women as suffering from septic or nonseptic abortions, as recorded on their hospital files, could be questioned.

\section{Health service factors}

For the selected interventions that were recorded as care received by the women, various descriptive words were used. They were for instance "given or not given," "administered or not administered," "done or not done," "recorded or not recorded," "complete or incomplete". The positive terms represented interventions implemented while the negative descriptive words depicted omissions of such interventions. Some of the variables were categorised under specific terms for rating and summation during analysis of the data.

\section{Pre-abortion risk factors}

Variables of contraceptives used and antenatal care booking status of women were considered to be pre abortion risk factors. Eighteen $(90,0 \%)$ out of 20 cases did not use any contraceptive method compared to $33(82,5 \%)$ of the control group. In both cases and controls, 95,0\% had not booked for antenatal care.

There was no statistically significant difference between cases and controls in the use of contraceptives ( $\mathrm{p}$-value $=$ $0.362, \mathrm{OR}=1.91,95 \% \mathrm{CI}=0.31-20.52$ ), suggesting that post abortion women who had and those who had not used contraceptives were equally at risk.

Similarly, there was no statistical significant difference between women who booked and those who had not booked for ante natal care ( $\mathrm{p}$-value $=$ $0.696, \mathrm{OR}=0.95,95 \% \mathrm{CI}=0.05-58.96$ ).

\section{Post abortion risk factors}

The selected post abortion care interventions included emergency care (summoning medical assistance, quarter to half hourly monitoring of blood pressure, temperature, respiration, pulse), oxytocic drug, antibiotic and analgesia administration. Other aspects of post abortion care included blood transfusion, evacuation of the uterus and follow-up care (hourly to four hourly monitoring of blood pressure, temperature, respiration, pulse) and documentation of care provided. (The variable, medical review, was excluded from the analysis because every woman was assessed daily by a doctor).

These health service factors (antenatal care, use of contraceptives prior to the current pregnancy, blood transfusion, evacuation of the uterus, oxytocic drug administration, antibiotic drug treatment and analgesia, follow-up care and documentation of care) were analysed using the Mantel-Haenszel Chi-Square Test or the Fischer's Exact Test to determine whether there were statistically significant differences. Where the number of cases or controls were small, the Fisher's Exact Test was used as an alternative to the MantelHaenszel Chi-Square Test to determine the $95 \% \mathrm{CI}$.

\section{Emergency post abortion care}

The majority of both cases $(65,0 \%)$ and controls $(90,0 \%)$ did not receive emergency post abortion care. Eleven $(55,0 \%)$ of the 20 cases were given blood transfusions compared to $11(27,5 \%)$ of the 40 controls. Twelve $(60,0 \%)$ of the 20 cases had an evacuation of the uterus performed for retained products of conception, compared to $37(92,5 \%)$ of the 40 controls. Ninety percent of the cases were given antibiotics compared to $34(85,0 \%)$ of the 40 controls.

In this study, there were more cases $(35,0 \%)$ than controls $(10,0 \%)$ to whom emergency post abortion care was rendered. However, a possible confounding variable, which could not be controlled by this retrospective casecontrol study, was the seriousness of the cases' physical conditions compared to those of the controls during and after 
admission to MCRH. The records could not be used to compile any accurate description of the seriousness of these two groups' physical conditions on and after admission to the MCRH. Consequently no inferences could be made concerning this potential confounding variable.

Selected aspects of standard of maternity care variables (table 1) that were "not given" or "not done" were exposure variables. When the risk of maternal mortality was analysed according to emergency care provided (calling of medical assistance, quarter to half hourly monitoring of blood pressure, temperature, respiration and pulse), the risk of dying decreased for women who had not received this care. The p-value = 0.025 indicated that there was a statistically significant difference in the deaths due to abortion between the women who had received emergency post abortion care and those who did not. This suggests that women to whom emergency post abortion care was not rendered had a better chance of surviving than those who received such care. The $95 \% \mathrm{Cl}=0.04-1.00$ for the OR (including 1) gave further evidence suggesting that where emergency post abortion care was not rendered, women had a better chance of surviving. However, one factor which could not be determined, was the women's physical condition prior to administration of emergency care. Although impossible to support from the patients' records, the possibility remained that only the critically ill women received emergency care and that the condition prior to receiving emergency care might indeed have been the critical factor in determining whether or not post abortion women survived or died, rather than the rendering or non-rendering of emergency care as such. Another possible variable which might have confounded the unexpected finding that cases received better reported care than controls, might have been the practice of reviewing maternal mortalities' files at management audit meetings. The expected audit of cases' files, might have influenced medical and nursing staff to record care given to these women more accurately than that recorded for controls where no audit of records by management was anticipated.

\section{The administration of analgesics}

The majority of cases $(70,0 \%)$ and controls $(85,0 \%)$ did not receive any form of analgesia to relieve pain associated with abortion complications. There was no difference in mortality risk in women who received analgesic drugs for pain relief and those who did not ( $\mathrm{p}$-value $=$ $0.152, \mathrm{OR}=0.41,95 \% \mathrm{CI}=0.09-1.86$ ). Although there was no statistically significant increased mortality risk associated with women not receiving analgesics, a review of women's records showed that a large number of both cases $(70,0 \%)$ and controls $(85,0 \%)$ endured pain without any analgesics. This occurred in spite of the availability of analgesics at the Mpilo Central Referral Hospital. It is well documented that pain increases shock while effective pain control measures could help to stabilise patients' conditions of shock.

\section{The administration of antibiotics}

The majority of women in both cases $(90,0 \%)$ and controls $(85,0 \%)$ were treated with antibiotics. There was no significant difference in the survival status between women who did and those who did not receive antibiotics ( $\mathrm{p}$-value $=0.461, \mathrm{OR}=$ $0.63,95 \% \mathrm{CI}=0.06-4.04$ ). However, this apparent lack of discrimination could be attributed to the fact that almost all women received antibiotics, rendering any statistical discriminatory analysis meaningless.

\section{The administration of oxytocic drugs}

One difference in treatment offered to cases and controls concerned the administration of oxytocic drugs for control of haemorrhage. Sixty percent of the cases compared to $90,0 \%$ of the controls were given oxytocic drugs. Women who did not receive oxytocic drugs were six times more likely to die than those who had received this treatment $(\mathrm{p}$-value $=0.01, \mathrm{OR}=6.00$, $95 \% \mathrm{CI}=1.28-31.28)$. This finding was supported in terms of proportions. In this study, there were more cases $(40,0 \%)$ than controls $(10.0 \%)$ to whom oxytocic drugs were not administered. Thus, it could be argued that oxytocic drugs could enhance women's chances of surviving post abortion complications.

\section{Evacuation of the uterus}

Evacuation of the uterus (to remove retained products of conception) was done for $60,0 \%$ of the cases and for $95,5 \%$ of the controls.

The results showed that the proportion of controls $(92,5 \%)$ who received an evacuation was higher compared to that of the cases $(60,0 \%)$. Women, who had not had an evacuation of the uterus following abortion were eight times more at risk of maternal mortality ( $\mathrm{p}$-value = $0.004, \mathrm{OR}=8.22,95 \% \mathrm{CI}=1.58-53.57$ ) than those who had uterine evacuations done. Evacuations might thus enhance women's chances of surviving post abortion complications by up to eight times.

\section{Administration of blood transfusions}

The risk of maternal mortality was analysed according to whether or not blood transfusions were done. Fifty-five percent of cases compared to $27,5 \%$ of controls received blood transfusions. The chances of survival were increased for women who had not received blood transfusion ( $\mathrm{p}$-value $=0.039, \mathrm{OR}=0.31$, $95 \% \mathrm{Cl}=0.09-1.10$ ). The OR for the $95 \%$ $\mathrm{CI}$ was less than $\mathrm{I}$, confirming that women who did not receive blood transfusions were less likely to die from post abortion complications. However, the cases had lower $\mathrm{Hb}$ levels than the controls, indicating a greater need for blood transfusions among the cases than among the controls. Therefore, it could be argued that even although the SPSS computer program indicated that women's chances of surviving post abortion complications were better if they received no blood transfusions, this statistical calculation does not account for the reason prompting the necessity for the blood transfusion in the furst place. Such reasons could be an extremely low Hb level or rapid loss of blood. A more accurate argument could then be based on this statistical result as indicating that women who did not require blood transfusions had enhanced chances of surviving post abortion complications than those who required such transfusions. Another issue which could have affected the patient outcomes after bluod transfusions related to the scarcity of blood donors in Zimbabwe. As potential donors might fear being informed about their HIV status, many Zimbabweans refrain from donating blood, even for emergency cases. Thus post abortion patients might not have received timely blood transfusions because of the non-availability of blood or because of delays in cross matching blood prior to transfusions (Mudokwenya-Rawdon 2001:158). However, these speculations could neither be supported nor refuted on the basis of the available records and will 
Table 1: Distribution of abortion cases and controls by selected implemented interventions for post abortion care for Mpilo Central Referral Hospital 1995-1997. OR and 95\% $\mathrm{Cl}(\mathrm{n}=60)$

\begin{tabular}{|c|c|c|c|c|c|c|c|}
\hline Factor & Cases & & Controls & & & & \\
\hline & $\mathbf{n}=\mathbf{2 0}$ & & $n=40$ & & & & \\
\hline & Number & $\%$ & Number & $\%$ & OR & $95 \% \mathrm{CI}$ & P-value \\
\hline \multicolumn{8}{|c|}{ Emergency post abortion care } \\
\hline Not given & 13 & $(65.0)$ & 36 & $(90.0)$ & \multirow{2}{*}{0.21} & \multirow{2}{*}{$0.04-1.00$} & \multirow{2}{*}{$0.025^{*} \mathrm{~F}^{*}$} \\
\hline Given & 7 & $(35.0)$ & 4 & $(10.0)$ & & & \\
\hline \multicolumn{8}{|c|}{ Oxytocic drug treatment } \\
\hline Not given & 8 & $(40.0)$ & 4 & $(10.0)$ & \multirow{2}{*}{6.00} & \multirow{2}{*}{$1.28-31.28$} & \multirow{2}{*}{$0.010 * \mathrm{~F}^{*}$} \\
\hline Given & 12 & $(60.0)$ & 36 & $(90.0)$ & & & \\
\hline \multicolumn{8}{|c|}{ Blood transfusion } \\
\hline Not Given & 9 & $(45.0)$ & 29 & (72.5) & \multirow{2}{*}{0.31} & \multirow{2}{*}{$0.09-1.10$} & \multirow{2}{*}{$0.039 *$} \\
\hline Given & 11 & (55.0) & 11 & (27.5) & & & \\
\hline \multicolumn{8}{|c|}{ Antibiotic drug treatment } \\
\hline Not Given & 2 & $(10.0)$ & 6 & $(15.0)$ & \multirow{2}{*}{0.63} & \multirow{2}{*}{$0.06-4.04$} & \multirow{2}{*}{$0.461 \mathrm{~F}^{*}$} \\
\hline Given & 18 & $(90.0)$ & 34 & $(85.0)$ & & & \\
\hline \multicolumn{8}{|l|}{ Analgesia } \\
\hline Not given & 14 & $(70.0)$ & 34 & $(85.0)$ & \multirow{2}{*}{0.41} & \multirow{2}{*}{$0.09-1.86$} & \multirow{2}{*}{$0.152 \mathrm{~F}^{*}$} \\
\hline Given & 6 & (30.0) & 6 & $(15.0)$ & & & \\
\hline \multicolumn{8}{|c|}{ Evacuation of the uterus } \\
\hline Not Done & 8 & $(40.0)$ & 3 & $(7.5)$ & \multirow{2}{*}{8.22} & \multirow{2}{*}{$1.58-53.57$} & \multirow{2}{*}{$0.004 * F^{*}$} \\
\hline Done & 12 & $(60.0)$ & 37 & (92.5) & & & \\
\hline
\end{tabular}

*Statistically significant at $95 \% \mathrm{CI}$

*F=Fisher's exact test

need to be subjected to further research. The only statistically substantiated research finding is that women who received blood transfusions had a greater chance of dying from post abortion complications than those women who did not receive blood transfusions.

\section{Completeness of records}

When the documentation of care was analysed for completeness, $80,0 \%$ of the cases' records were incomplete compared to $95,5 \%$ of records belonging to the controls. Documentation of care offered to women was measured in terms of "completeness" or "incompleteness" of records. Documentation was considered incomplete when one or more aspects of data had been missing in the woman's obstetric records. The results revealed major deficiencies regarding documentation. This variable was not significantly associated with the risk of maternal death (p-value $=0.159, \mathrm{OR}=$ $0.32,95 \% \mathrm{CI}=0.04-2.20$ ) reflecting that women's survival status was not influenced by the absence or presence of complete records. This was applicable to "incomplete" records belonging to both controls $(92,5 \%)$ and cases $(80,0 \%)$.

Follow-up care analyses included one to four hourly monitoring of blood pressure, temperature, respiration and pulse. There was no significant maternal mortality risk associated with the presence or absence of follow-up care ( $\mathrm{p}$-value $=0.089, \mathrm{OR}=$ $0.21,95 \% \mathrm{CI}=0.02-1.69)$ at the $5 \%$ level of significance. 
Table 2: Comparison between abortion cases and controls by selected aspects of standard of maternity care factors, proportion and p-value for Mpilo Central Referral Hospital 1995-1997 ( $n=60$ )

\begin{tabular}{|l|c|c|c|}
\hline \multirow{2}{*}{$\begin{array}{l}\text { Standard of maternity care } \\
\text { factor }\end{array}$} & $\begin{array}{c}\text { Proportion of cases } \\
\text { provided with care }\end{array}$ & $\begin{array}{c}\text { Proportion of controls } \\
\text { provided with care }\end{array}$ & $\begin{array}{c}\text { Difference between } \\
\text { proportions }\end{array}$ \\
\cline { 2 - 4 } & $\mathrm{n}=20$ & $\mathrm{n}=40$ & \\
\cline { 2 - 4 } & Percent & Percent & Normal distribution p-values \\
\hline Emergency care given & 35.0 & 10.0 & 0.038 \\
\hline Oxytocic drug treatment given & 60.0 & 90.0 & 0.095 \\
\hline Blood transfusion & 55.0 & 27.5 & 0.068 \\
\hline Evacuation of the uterus & 60.0 & 92.5 & 0.077 \\
\hline Analgesics given & 30.0 & 15.0 & 0.136 \\
\hline $\begin{array}{l}\text { Antibiotics drug treatment } \\
\text { given }\end{array}$ & 90.0 & 85.0 & 0.421 \\
\hline Follow up care given & 20.0 & 5.0 & $0.00003^{*}$ \\
\hline $\begin{array}{l}\text { Documentation of care } \\
\text { (complete records) }\end{array}$ & 20.0 & 7.5 & 0.125 \\
\hline
\end{tabular}

*Statistically significant at $0.025 \mathrm{p}$-value

\section{Review of hypotheses tested}

The two-tailed test for normal distribution was used to determine p-values for the differences between proportions of abortion cases and controls with the same characteristics.

Comparison between abortion cases and controls by selected physiological factor, proportion and p-value.

Hypothesis 1: There is a difference in selected physiological factors (Hb level and temperature) associated with maternal mortality due to abortion between non-surviving (cases) and surviving (controls) women hospitalised at the Mpilo Central Referral Hospital from 1 January 1995 to 31 December 1997.

The two-tailed test was used to determine the differences between proportions for normal haemoglobin values and temperature levels between cases and controls. The hypothesis was rejected in terms of haemoglobin level. Statistically, there was no significant difference in the proportions between $\mathrm{Hb}$ levels of cases and controls for (normal $\mathrm{Hb}$ level $>11 \mathrm{~g} / \mathrm{dl}$ ), $\mathrm{p}$-value $=0.156$ )
However, in clinical terms, the proportion of cases $(31,2 \%)$ with a normal Hb level $(>11 \mathrm{~g} / \mathrm{dl}$ ) was less than that of the controls $(45,7 \%)$ indicating a higher prevalence of anaemia among cases than controls.

When comparisons were made for temperature levels, the hypothesis was supported. There was a significant difference in proportions between cases and controls ( $p$-value of 0.015 ). The proportion $(60,0 \%)$ of controls who had normal temperatures $\left(36.0-37.5^{\circ} \mathrm{C}\right)$ was higher than that of the cases $(31,6 \%)$. This indicated that pyrexia (temperature $>37.5^{\circ} \mathrm{C}$ ), a sign of sepsis, was more common among the women who died than those who survived.

Comparison between abortion cases and controls by selected aspects of standard of maternity care factor, proportion and p-value.

Hypothesis 2: There is a difference in selected aspects of standard of care received by non-surviving (cases) and surviving (controls) women hospitalised for abortion at MCRH.

The hypothesis was rejected in terms of emergency care (emergency care p-value
$=0.038)$, blood transfusion ( $\mathrm{p}$-value $=$ 0.068 ), analgesia ( $p$-value $=0.136$ ), antibiotic treatment $(\mathrm{p}$-value $=0.421)$ and documentation of care ( $\mathrm{p}$-value $=0.125$ ). However, from a clinical standpoint, the proportions of cases, for all these variables, were higher than those of the controls. For emergency care, blood transfusion, antibiotic drug treatment and documentation of care, a higher proportion of the women who died received these aspects of care than those who survived.

However, for oxytocic drug treatment and evacuation of the uterus the proportions of controls were higher compared to the cases. The hypothesis was supported for follow-up care, which was significant. The p-value (0.00003), which is less than 0.025 , showed that there was a statistically significant difference between cases and controls. The finding shows that the cases were rendered better recorded follow-up care than the controls.

Significant factors associated with abortion and risk of mortality by adjusted Odd Ration and P-value

Hypothesis 3: The association of selected health service factors (emergency care, oxytocic drug treatment, 
blood transfusion and evacuation of the uterus) with maternal mortality due to abortion in non-surviving (cases) and surviving (controls) women hospitalised at the MCRH will hold after adjusting for confounding variables (residence, age, marital status, occupation and gravidity).

Significant factors associated with maternal mortality that were identified by use of the Mantel-Haenszel Chi-Square Test or Fisher's Exact Test on the post abortion sample data were further analysed for significance using stepwise logistic regression after adjusting for confounding variables. The hypothesis was supported for

$$
\begin{aligned}
& \text { emergency care ( } \mathrm{p} \text {-value = } \\
& 0.018, \mathrm{OR}=3.28) \text { and } \\
& \text { blood transfusion ( } \mathrm{p} \text {-value = } \\
& 0.026, \mathrm{OR}=4.48) .
\end{aligned}
$$

The variables of emergency post abortion care and blood transfusion remained significantly associated with decreased risk of maternal mortality, further confirming that a woman who did not receive emergency post abortion care and/or a blood transfusion was less likely to die than the one who was given such care.

When proportions of cases and controls were compared for differences regarding the standard of care for post abortion patients, the results suggest that women who died appeared to have received better recorded care than those who survived.

\section{Significant findings about the importance of evacuation of the uterus and the administration of oxytocic drugs}

Women were eight times more at risk of dying from post abortion complications if they did not have an evacuation of the uterus done; and six times more at risk from dying if they did not receive oxytocic drug treatment for treating post abortion complications.

\section{Discussion of research findings}

In this study post abortion mortalities neither supported nor refuted the significance of sepsis by itself. Of significant importance was the finding that a combination of sepsis, anaemia, advancing age, high gravidity and socioeconomic status reflected by high unemployment, seemed to have compromised the resilience of the post abortion women who died. Contraceptive use is a cornerstone for preventing unwanted pregnancies. The reasons why the majority of post abortion women failed to use contraceptives could not be established during the course of this study because various family planning methods were available in Zimbabwe during that time.

Process intervention outcomes revealed that women died despite being provided with better quantitative recorded care than those who survived. Factors such as advancing age, high gravidity, anaemia and low socio-economic status (reflected by the high unemployment rates) might have compromised the women's resilience to post abortion complications such as sepsis and haemorrhage. Post abortion emergency care is an area of considerable importance in influencing the women's chances of survival, but the women must seek this service timeously to experience maximum benefits. It is possible that the women who died were admitted for care when their physiological responses to treatment had already been compromised.

The findings that cases were provided with better recorded care than the controls were unexpected. Maine (1991:16) asserted that more women die from pregnancy related complications when they have been provided with substandard care. In this study, the reason why women died, despite having been offered better recorded care than the survivors might be embodied in two determinant factors.

Firstly, each woman brings with her into the health care system personal factors influencing her responses to the care provided. Factors such as pre-existing debilitating undiagnosed diseases, such as HIV/AIDS and malaria and/or tuberculosis, might have influenced women's chances of responding favourably to treatment. Furthermore, although women who died reportedly received better documented care, physiologically women's responses to treatment might have been influenced by their resilience to post abortion complications. This could be neither confirmed nor denied from studying these patients' obstetric records. However these results appeared to be contrary to expectations. The reason for this could be that nurses normally ensure that records of dying patients are complete in view of the anticipated maternal mortality review committee's investigations. Unfortunately, the assumption exists worldwide that midwifery/nursing records are not always true reflections of the care rendered, and might show an incomplete picture of the interventions provided (Hale, Thomas, Bond \& Todd 1997:213). It seemed possible that controls' records of treatment and care received might have been more incomplete than those of cases. Nevertheless, only the records were available for study and the only conclusion reached was that cases' files portrayed better recorded care than those of controls.

\section{Limitations of the research}

The major limitation was that data were collected from one hospital because of non- forthcoming permission from other health institutions with similar functions in Zimbabwe. The results, therefore, cannot be generalised to other health care institutions, without repeating similar research projects at other sites. Studying predated rather than current records might impose further restrictions on the generalisability of the research results. Nevertheless, the retrospective obstetric records audit played a central role in providing insights into factors associated with mortality due to post abortion complications.

Other limitations arose because of the non-accessibility of specific patients' records which made sampling impossible, amounting to convenience sampling in utilising those records of post abortion cases and controls which could be accessed. As there can be no guarantees that the records which were accessible were identical to those which were inaccessible, this might limit the generalisability of the research results. An unexpected limitation related to the inadequacy of the accessible records. Unrecorded data could not be accounted for and was treated as "missing data" which possibly further limits the generalisability of the research results.

The women's unknown HIV, unknown TB and unknown malaria status might have impacted on the post abortion outcomes. A significant limitation on the generalisability of the research results, relates to the absence of indications as to the women's general state of health and well-being in the patients' records. 
Recommendations for improving care rendered to women with post abortion complications in Zimbabwe

As post-abortion complications continue to contribute significantly to the maternal mortality statistics in Zimbabwe, rendering improved care to these women should reduce the overall number of maternal mortalities in this country. The following recommendations should enable health care workers to begin to realise this objective of reducing maternal mortalities:

- $\quad$ clearly formulated policy guidelines for the treatment of women with post abortion complications should be compiled and supplied to all health care institutions; such guidelines should include:

- indications for evacuating the uterus (increasing women's chances of survival eight fold in this research)

- administration of oxytocic drugs (increasing women's chances of survival six fold in this research)

- administration of analgesics - a neglected aspect in this research

- administration of antibiotics given to almost all women in this study - but a practice of debatable merit unless the women have elevated temperatures (May et al 2000:5).

In-service education should be provided to all health care workers rendering services to women with post abortion complications, emphasising which life saving measures should be instituted.

\section{Conclusions}

The results demonstrated that antibiotic drug treatment, the administration of analgesic drugs, follow-up care and documentation of care were not significantly associated with maternal mortality due to abortion. On the other hand, oxytocic drug treatment and evacuation of the uterus were significantly associated with a higher risk of maternal death for those women did not receive these treatments. Contrary to expectations, it appeared that women who were not provided with emergency care or who did not receive blood transfusions were at lower risk of dying from post abortion complications than those women who received these treatments.

The critical issue remains that abortion deaths are preventable. The possibility of reduction is real if doctors and nurses/ midwives respond to the women's needs in good time and provide good quality care implying "... that it is client-oriented and sensitive to the needs of communities and individuals, and that it maintains high technical quality through adoption of sound norms and standards...."(WHO 1999:36).

Unless and until effective contraceptive and emergency contraceptive services are available to all women of Zimbabwe, they are likely to continue to resort to back street abortionists and to die from post abortion complications. This research has indicated that women's chances of surviving post abortion complications are enhanced by evacuating the uterus and by administering oxytocic drugs. However, even these potentially life saving measures are merely addressing the symptoms of the underlying problem of Zimbabwe's women's inability to access contraceptives and emergency contraceptives and the fact that the termination of unwanted pregnancies remains illegal in this country.

\section{List of references}

ABOUZAHR, C \& ROYSTON, C. 1991: Maternal mortality: a global fact book. Geneva: World Health Organization.

ABRAMSON, JH. 1990: Survey methods in community medicine: an introduction to epidemiology and evaluative studies. $3^{\text {rd }}$ edition. London: Churchill Livingstone.

ASHWORTH, MF. 1990: Harare Hospital maternal mortality for 1987 and a comparison with previous reports. Central African Journal of Medicine. 36:209-211.

BANTA, D.1992: Developing outcome standards for quality assurance activities. Quality Assurance in Health Care, 4(1):25-32.

BENNETT, RV \& BROWN, LK. 1999: Myles textbook for midwives. $13^{\text {th }}$ edition. London: Churchill Livingstone.

BURNS, N \& GROVE, SK. 2001: The practice of nursing research: conduct, critique and utilization. $4^{\text {th }}$ Edition. Philadelphia: WB Saunders.

DONABEDIAN, A. 1988: The quality of care: how can it be assessed? Journal of the American Medical Association. 260(12): 1743-1748.

DONABEDIAN, A. 1989: Institutional and professional responsibilities in quality assurance. Quality Assurance in Health Care. 1 (1):3-11.

HALE, CA, THOMAS, LH, BOND, S \& TODD, C. 1997: The nursing record as a research tool to identify nursing interventions. Joumal of Clinical Nursing. 6:207-214

KAHN, HA \& SEMPOS, CT. 1989: Statistical methods in epidemiology. New York: Oxford University Press.

LINDBERG, JB, HUNTER, ML, KRUSZEWSKI, AN. 1994: Introduction to nursing concepts, issues and opportunities. 2nd edition. Philadelphia: JB Lippincott.

MAINE, D. 1991: Safe motherhood progams: options and issues. Prevention of maternal mortality. Center for Population and Family Health. United States of America.

MAY, W, GULMEZOGLU, AM \& BATHIKE, K. 2000: Antibiotics for incomplete abortion (Cochrane Review). The Cochrane Library, Issue 1. Oxford: Update Software.

MCRH see Mpilo Central Referral Hospital

MINISTRY OF HEALTH. 1981: Planning for equity in health: a sectoral review and policy statement. Harare: Zimbabwe Ministry of Health \& Child Welfare.

MOH see Ministry of Health

MPILO CENTRAL REFERRAL HOSPITAL. 1996: Annual report. Bulawayo: Mpilo Central Referral Hospital.

MPILO CENTRAL REFERRAL HOSPITAL OBSTETRIC/ GYNAECOLOGICAL RECORDS. 1997: Bulawayo: Maternity Units. Bulawayo: Mpilo Central Referral 
MUDOKWENYA-RAWDON, C. 2001:

Factors influencing pregnancy outcome in high-risk patients. Pretoria: University of South Africa. (D Litt et Phil thesis).

MUNRO, BH. 1997: Statistical methods for health research. New York: JB Lippincott.

NAAOG see Nurses' Association of American College of Obstetricians \& Gynecologists.

\section{NURSES' ASSOCIATION OF AMERICAN COLLEGE OF OBSTETRICIANS GYNAECOLOGISTS. 1990 : \\ Obstetricians, gynecologists and nursing practice resource: quality assurance. Washington, DC: The Organization for Obstetric and Gynecologic \& Neonatal Nurses 409, 12 Street, SW.}

OXFORD ADVANCED LEARNER'S DICTIONARY. 1989: Oxford: Oxford University Press.

\section{OXFORDHANDY DICTIONARY. 1990}

London: Chancellor Press.

POLIT, DF. \& HUNGLER, BP. 1995: Nursing research: principles and research. $5^{\text {th }}$ edition. New York: JB Lippincott.

ROYSTON, E \& ARMSTRONG, S 1989: Preventing maternal mortality. Geneva: World Health Organization.

STARRS, A. 1997: The safe motherhood action agenda: priorities for the next decade. A report on the safe motherhood technical consultation 18-23 October 1997 Colombo, Sri Lanka. New York: Family Health International.

TALBOT, LA. 1995: Principles and practice of nursing research. St Louis: CV Mosby.

WHO see World Health Organization.

WINKLER, J, OLIVERAS, E \& MCINTOSH, N. 1995: Post abortion care: a reference manual for improving quality of care. United States of America: Post abortion care Consortium. data on the frequency and mortality of
WHO.

WORLD HEALTH ORGANIZATION. 1998A: Almost 20 million unsafe abortions each year. Safe Motherhood Newsletter of World Activity, 26(2):2.

WORLD HEALTH ORGANIZATION. 1998B: Unsafe abortion: global and regional estimates of incidence of and mortality due to unsafe abortion with a listing of available country data RHT/ MSM/97.16. $3^{\text {rd }}$ edition. Geneva: WHO.

WORLD HEALTH ORGANIZATION. 1999: Reduction of maternal mortality: a joint WHO/UNFPA/UNICEF/World Bank Statement. Geneva: WHO. 